\title{
Liquid phase epitaxy set-up designed for in situ X-ray study of SiGe island growth on (001) Si substrates
}

\author{
Th. Teubner**1 ${ }^{*}$ U. Jendritzki ${ }^{1}$, K. Böttcher ${ }^{1}$, G. Schadow ${ }^{1}$, R. Heimburger ${ }^{1}$, A.-K. Gerlitzke ${ }^{1}$, \\ S. Deiter ${ }^{2}$, Ch. Eisenschmidt ${ }^{2}$, T. Boeck ${ }^{1}$, R. Fornari ${ }^{1}$, and M. Hanke ${ }^{2}$ \\ ${ }^{1}$ Leibniz-Institut für Kristallzüchtung, Max-Born-Straße 2, 12489 Berlin, Germany \\ ${ }^{2}$ Martin-Luther-Universität Halle-Wittenberg, Institut für Physik, Hoher Weg 8, 06120 Halle/Saale, \\ Germany
}

Received 8 July 2008, revised 8 September 2008, accepted 9 September 2008

Published online 10 November 2008

Key words silicon, germanium, pyramids, solution growth, bismuth, in situ HRXRD, equipment, sample preparation.

PACS 06.60.Ei, 07.05.Fb, 07.20.Hy, 81.10.Dn, 81.15.Lm, 81.16.Dn

In situ X-ray examination at a synchrotron beamline of the solution growth of self-assembled SiGe structures on silicon (001) substrates through the backside has been realized by a specific heating equipment and a suitable growth assembly. The furnace allows heating of the growth assembly up to $600{ }^{\circ} \mathrm{C}$. The temperature field and the gas flow in the furnace have been numerically modeled. In this way a meaningful estimate about the power consumption and the thermal gradient across the sample has been reached. Despite its low heat capacity and, thus, fast heating and cooling ability the furnace can be stabilized to $\pm 0.1 \mathrm{~K}$ by a highperformance temperature controller. The growth assembly has been prepared within three separate stages carried out in conventional slideboat liquid phase epitaxy equipment. Such growth assembly allows carrying out then intended experiments without $\mathrm{H}_{2}$ as normally used in liquid phase epitaxy in favor of $\mathrm{N}_{2}$, meeting the demand of minimized risks at beamlines. The equipment ensures an easy handling of the growth assembly.

(C) 2008 WILEY-VCH Verlag GmbH \& Co. KGaA, Weinheim

\section{Introduction}

Ex situ characterization of self-assembled pseudomorphic SiGe structures on silicon substrates grown by the Stranski-Krastanov mode from metallic solutions has been the subject of basic research for more than a decade. Such samples have been characterized by a variety of methods like scanning electron microscopy (SEM), atomic force microscopy (AFM), transmission electron microscopy [1], electron energy loss spectroscopy [2], micro-Raman investigation [3], grazing incidence X-ray diffraction [4], and high-resolution X-ray diffraction (HRXRD) [5].

Liquid phase epitaxy (LPE) offers, contrarily to other epitaxial methods, like molecular beam epitaxy or chemical vapor deposition, the unique opportunity to crystallize SiGe with only minor deviations from the thermodynamical equilibrium. Consequently, the growth results in case of $\operatorname{Si}(001)$ substrates in well developed truncated pyramids with $\{111\}$ side facets.

Bismuth as a solvent has two advantages in comparison to other low melting metals. The low solubility of $\mathrm{Si}$ and $\mathrm{Ge}$ in bismuth at temperatures of $500-600^{\circ} \mathrm{C}$ allows the precise control of supersaturation at low cooling rates and, thus, leads to low growth rates. Due to the low degree of supersaturation attainable in LPE the strain mediated growth of SiGe structures stops when the final shape has been reached [6]. Thus, the time to stop the experiment and remove the solution can easily be fixed. The size of the pyramids shrinks from $6 \mu \mathrm{m}$ to $60 \mathrm{~nm}$ with an increasing amount of $\mathrm{Ge}$ in the liquid phase over the range where pseudomorphic growth takes place [7]. The second advantage of Bi solvent consists in the comparable low surface free energy that promotes three-dimensional growth in favor to two-dimensional layer growth [8].

\footnotetext{
* Corresponding author: e-mail: teubner@ikz-berlin.de 
The evolution of pyramid morphology, preserved by interrupting the growth prior to the final stage, has been investigated by AFM [5]. Concerning the morphology the hereby-attained results point to a growth process starting with high indexed facets that convert finally into $\{111\}$ planes. In situ HRXRD is suitable to check this model. However, a very specific growth assembly is needed.

Typically, for ex situ investigations, conventional slideboat LPE of SiGe from metallic solvents is carried out. Such an equipment allows both loop-controlled heating of a multi-zone furnace to provide isothermal conditions up to $930{ }^{\circ} \mathrm{C}$ in the growth zone under Pd-diffused ultra-pure hydrogen atmosphere and mechanical movement of the solution to initiate and finish the contact of solution with an usually face up positioned substrate. Such a LPE growth of SiGe pyramids has to be carried out within two separate stages whereas opening of the reactor in the meantime is unavoidable. Due to the low solubility of $\mathrm{Si}$ in bismuth (about $8 \mathrm{ng}$ per gram $\mathrm{Bi}$, calculated for $600{ }^{\circ} \mathrm{C}$ [9]) the addition of weighed quantities of $\mathrm{Si}$ is not practicable. Therefore, the first stage comprises of the in situ saturation of $\mathrm{Bi}$ with $\mathrm{Si}$ from a feeding substrate at the desired growth temperature. The growth proceeds during the second stage by adding an adequate, weighed amount of Ge (in the milligram-range) to the solution. In both stages a high temperature step of $930^{\circ} \mathrm{C}$ is necessary to remove the thin native oxide from the Si surface to enable dissolution or epitaxial growth.

Usually, the front side of substrates with grown SiGe islands, which is free from residual solvent after the LPE run, can be directly exposed to ex situ X-ray diffraction investigations. Contrary, in situ X-rays studies of the growth of SiGe can be exclusively performed through the backside of the sample. The metallic solution, which is covering during the experiment the front side of the sample, is impenetrable for X-rays. Sufficient beam intensity for such experiments is available from synchrotron sources. Nevertheless, the thickness of the substrates has to be much lower than usually applied in semiconductor layer growth. The operational conditions in synchrotron facilities do not allow the incorporation of a conventional LPE apparatus. There are severe restrictions in space and in applying dangerous media.

The development of an manageable heating equipment and the preparation of a growth assembly guaranteeing the epitaxial growth of $\mathrm{SiGe}$ structures on $\mathrm{Si}(001)$ substrates at temperatures of $500-600{ }^{\circ} \mathrm{C}$ under the experimental limitations of the beamline BW2 at the HASYLAB synchrotron facility DORIS III [10] has been a challenging task as reported in the following sections.

\section{Experimental}

The above-mentioned limitations for carrying out X-ray diffraction experiments at a synchrotron beamline pose stringent requirements to furnace design. A suitable growth assembly, intended as crucible-substratemetallic solution ensemble, has to be prepared. Both tasks go beyond the demands usually met in LPE growth.

Furnace Figure 1 shows a sectional drawing of the furnace for in situ X-ray diffraction measurements (Xoven). The BW2 measuring station determines the radius of the base flange to $50 \mathrm{~mm}$ and the position of the Si substrate at $125 \mathrm{~mm}$ above the flange. The usable space on both sides and behind the $\mathrm{X}$-oven extends to a radius of circa $150 \mathrm{~mm}$. The Si substrate has to be positioned face down at BW2.

Fig. 1 Sectional drawing of the X-oven: 1 - Be dome, 2 - thermocouple feedthrough, 3 - inlet/outlet tubes for water cooling, 4 - exhaust bellow, 5 - electrical power feedthroughs, 6 - gas inlet/outlet, 7 - ceramic housing of the heated zone with top heater, 8 - probe stage, 9 - Xray beam, pointing to the backside of the Si substrate, 10 - direction of the symmetrical 004 reflection.

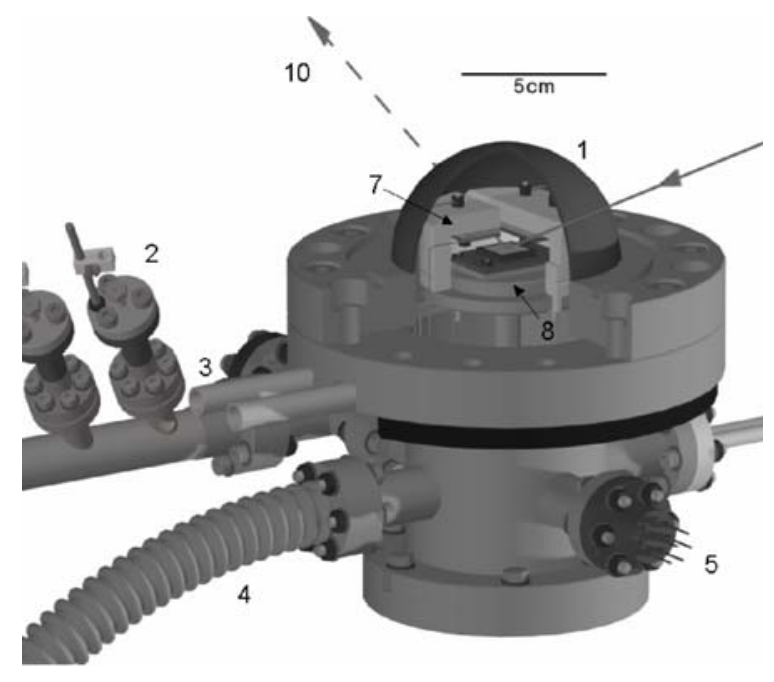


The interior of the X-oven is schematically shown in figure 2. A graphite crucible $(15 \mathrm{~mm} \times 15 \mathrm{~mm} \times 2.5 \mathrm{~mm})$ containing the $\mathrm{Bi}$ solvent and the $\mathrm{Si}$ substrate (growth assembly) is surrounded by three specially designed heaters consisting of rectangular ceramic plates which are bearing boron nitride encapsulated heating elements made of pyrolytic graphite. The bottom heater $\left(35 \times 25 \mathrm{~mm}^{2}\right)$ is covered by a stack of three Si plates. Thus, a more uniform distribution of heat can be reached. Between the lower two plates slits are engraved to fix the thermocouples TC3 and TC4 for control and monitoring purposes. TC3 is positioned in the centre and TC4 in a distance of $5 \mathrm{~mm}$ apart from it. The uppermost of the three plates has a square opening to take up the growth assembly in a predefined position.

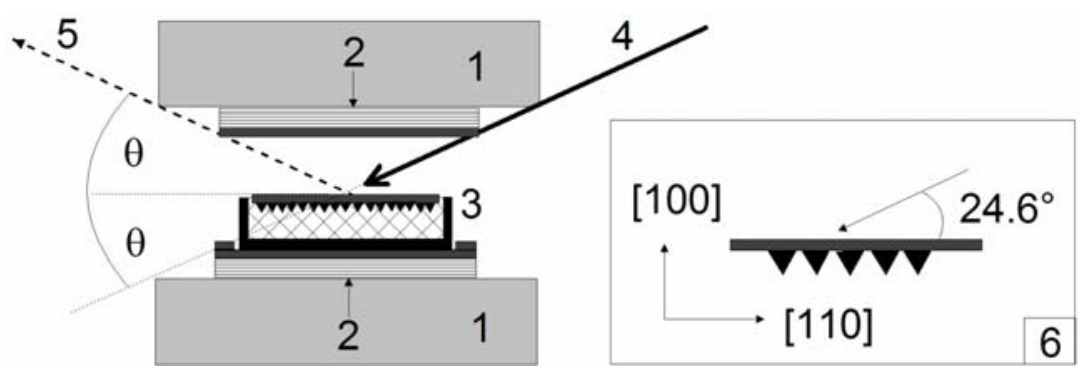

Fig. 2 Schematic representation of the interior design of the heated zone of the X-oven: 1 - ceramic housing parts, 2 - heater covered by Si plates, 3 - growth assembly, 4 - incident X-ray beam, 5 symmetrical Si 004 reflection, 6 - beam/substrate alignment.

Both top heaters leave a gap in-between to allow the passage of the X-ray beam. Two Si plates per heater fix the thermocouples in the same way as for the bottom heater to enable temperature control. A vertical clearance of $5 \mathrm{~mm}$ exists between top heaters $\left(15 \times 25 \mathrm{~mm}^{2}\right)$ and growth assembly. The hot zone is encapsulated by a ceramic housing that has a removable part on one side. In combination, both features allow the proper loading and unloading of the growth assembly. A slit across the cap of the housing makes the beam passage possible. All these parts, forming the probe stage, are fixed to the bottom by a slender ceramic pedestal.

The hot parts are shielded from outside by an HV-tight stainless-steel chamber capped with a hemispherical thin-walled Be-dome serving as X-ray window. The Be-dome is mounted on a DN100CF flange whose counterpart is water-cooled. One multi-pin feedthrough for the power cables, five individual feedthroughs with pull relief for thermocouples, one gas inlet, one gas outlet, and one DN16KF flange for connecting a vacuum pump complete the stainless steel chamber.

Temperature control of the three heaters has been realized by a Eurotherm 2704 high-performance multiloop controller in combination with a power supply especially designed to the maximum power of bottom and both top heaters of $220 \mathrm{~W}$, and of $90 \mathrm{~W}$ each, respectively.

After evacuating to about $200 \mathrm{mPa}$ the chamber is refilled - other than in conventional LPE - with $\mathrm{N}_{2}$ to atmospheric pressure. During heating the gas outlet valve is opened and the inert gas is flushing the chamber at a low rate.

Preparation of the growth assembly The growth assembly was prepared in a conventional slideboat LPE equipment under Pd-diffused hydrogen in three consecutive steps opening each time the reactor to ambient air for loading/unloading: (1) saturation of $\mathrm{Bi}$ with $\mathrm{Si},(2)$ covering the thin $\mathrm{Si}$-substrate with the $\mathrm{Si}$ containing solution at low temperatures, (3) fitting the thin substrate with adhering solution into the graphite crucible.

During the first preparation step both the feeding substrate inserted into a recess of the graphite carrier and a portion of about $6 \mathrm{~g} \mathrm{Bi}$ in the opening of a graphite slider (cross sectional area of $10 \times 10 \mathrm{~mm}^{2}$ ) are heated to $930{ }^{\circ} \mathrm{C}$ and maintained at this temperature for $30 \mathrm{~min}$ to remove the oxide coverage from the surface of the $\mathrm{Si}$ source. Then, the temperature is lowered to the intended saturation temperature $\left(500-600{ }^{\circ} \mathrm{C}\right)$. The $\mathrm{Bi}$ melt is brought into contact with the Si source, allowing saturation for $180 \mathrm{~min}$, and then withdrawn from the source and cooled to room temperature.

The second preparation step requires a modified graphite carrier enabling the fixation of the thin $\mathrm{Si}$ substrate at the bottom of a recess by a graphite frame. The experimental conditions at the BW2 station of HASYLAB, concerning the available beam power and detection sensitivity, restrict the thickness of such substrates to about $30 \mu \mathrm{m}$. Therefore, $10 \times 10 \mathrm{~mm}^{2}$ plates have been cleaved parallel to $<110>$ directions from Czochralski-grown $\mathrm{Si}(001)$ double side polished wafers (50.8 $\mathrm{mm}$ diameter), $25 \pm 5 \mu \mathrm{m}$ thick. The phosphorus- 
doped material has an electrical resistivity of $5-20 \Omega \cdot \mathrm{cm}$. The removal of surface oxide from the substrate at $930{ }^{\circ} \mathrm{C}$, and the homogenization of the solution as well, are followed by lowering the temperature to the same value as applied for saturation in the first step. Then, the solution is transferred onto the substrate. After withdrawal of the slider a defined quantity of solution remains in contact with the substrate in the recess. The natural cooling to room temperature finishes this cycle.
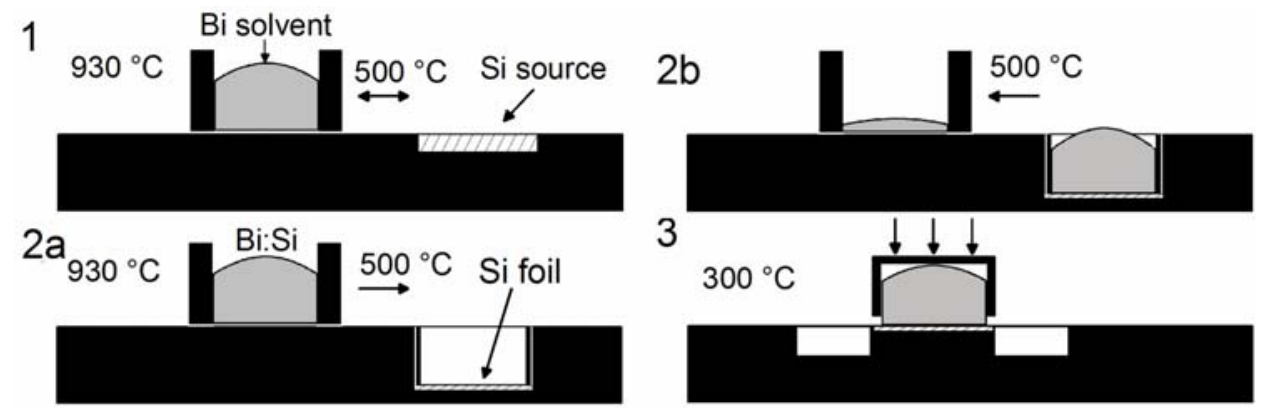

Fig. 3 Steps of preparation of the growth assembly in a conventional LPE equipment: (1) Desorption of native oxide from the $\mathrm{Si}$ source at $930{ }^{\circ} \mathrm{C}$ and $\mathrm{Si}$ saturation of $\mathrm{Bi}$ at desired growth temperature - here $500{ }^{\circ} \mathrm{C},(2 \mathrm{a}, \mathrm{b})$ Desorption of native oxide from the Si foil at $930{ }^{\circ} \mathrm{C}$ and covering the thin Si substrate with the solution at desired growth temperature, and (3) fitting the substrate with adhering solution into the graphite crucible at $300{ }^{\circ} \mathrm{C}$. For detailed explanation of the procedure see text.

The third step takes place at $300{ }^{\circ} \mathrm{C}$ (slightly above the melting point of Bi). During this process the solution is fitted exactly to the geometry of the graphite crucible. The substrate with adhering Bi melt and Si crystallites is capped by a top-down positioned crucible. A graphite body loads that crucible and acts as a stamp to press the crucible down when melting of $\mathrm{Bi}$ takes place. Redundant solvent is eliminated and collected in a recess surrounding the pedestal that is supporting the substrate. The solidified, Si containing Bi ingot does not adhere to graphite. Thus, crucible and ingot can be separated to insert a Ge grain prior to the X-ray experiment.

As will be shown later, the bending of $30 \mu \mathrm{m}$ thin substrates in contact to $\mathrm{Ge}$ is unavoidable. Thus, the substrate has to be mechanically stabilized prior to the in situ X-ray experiments. A $550 \mu \mathrm{m}$ thick Si platelet has been glued on the backside using the high temperature graphite adhesive Resbond 931 of Cotronics. The fixings have a hole in the centre to enable the incidence of the X-ray beam. Two opening shapes (circle with a diameter of $6 \mathrm{~mm}$ and rectangle with edge lengths of $3 \mathrm{~mm}$ and $6 \mathrm{~mm}$ ) as shown in figure 4 have been used. The complete growth assembly is shown in figure 4. For examination of grown $\mathrm{SiGe}$ after the experiments the adhering $\mathrm{Bi}$ solvent has been removed from the surface of the sample by etching at a temperature of $60{ }^{\circ} \mathrm{C}$ in an aqueous solution of $5.8 \mathrm{~mol} \cdot \mathrm{L}^{-1} \mathrm{HNO}_{3}$.

Fig. 4 Cross sectional view of the growth assembly prior to the $\mathrm{X}$-ray investigation consisting of graphite crucible, Bi solvent, Ge grain, thin $\mathrm{Si}(001)$ substrate, and fixing platelet (left) and top view of two variants of fixing platelets.
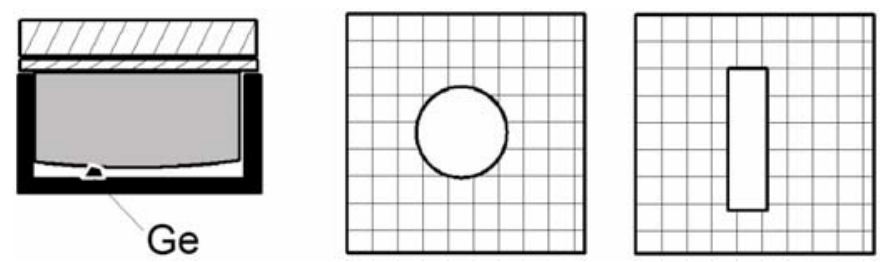

HRXRD configuration To monitor the evolution of the islands during the growth a special deflection optic leads the X-ray beam with the required angel of incidence (cf. Fig. 2) on the sample in the X-oven. The distribution of the diffusely scattered intensity is recorded by an area detector (SMART APEX CCD detector) and correlated to the growth temperature.

\section{Modeling}

Thermal field of furnace The development of temperature field and gas flow in the furnace has been numerically investigated especially for two purposes: (1) to obtain reasonably good values for the capacity of 
the two heaters in order to reach a maximum temperature of $600{ }^{\circ} \mathrm{C}$ in the center of the solvent surface, and (2) to make sure that the temperature field within the Bi solvent has only very small temperature gradients.

The computations have been done with the Finite Element Package FIDAPTM. An axisymmetric geometry and steady state conditions have been selected. The geometry implies that the heaters in the model are a ring (top) and a disc (bottom). Heat conduction and radiation exchange between all internal surfaces of the furnace have been considered as heat transport mechanisms. The outer surface of the furnace loses heat towards the laboratory conditions. Natural convection within the solvent was not considered for this computation.

Calculation of bending of thin substrates A simple analytical model for lattice misfit induced substrate bending in the case of heteroepitaxy has been given by OLSEN and ETTENBERG [11]. The bending radius of a stack of $n$ layers having each the thickness $t_{i}$ and a relative misfit $\varepsilon_{i j}$ between the $\mathrm{i}^{\text {th }}$ and the $\mathrm{j}^{\text {th }}$ layer is:

$$
r=\frac{\left(\sum_{i=1}^{n} t_{i}\right)^{3}}{6 \sum_{i=1}^{n} \sum_{j>i}^{n} t_{i} t_{j} \varepsilon_{i j}} .
$$

To estimate the upper limit of such bending effects of thin (001) Si foils the growth of pure Ge layers have been assumed. Then, the above equation reduces to

$$
r=\frac{\left(t_{S i}+t_{G e}\right)^{3}}{6 t_{S i} t_{G e} \frac{a_{0}^{G e}-a_{0}^{S i}}{a_{0}^{S i}}}
$$

with $t_{S i}$-thickness of Si substrate, $t_{G e}$-thickness of Ge layer, and $a_{0}^{S i}, a_{0}^{G e}$ - lattice constants of silicon and germanium, respectively. Due to the larger lattice constant of Ge the bending has to be concave when looking at the substrate from the backside.

\section{Results and discussion}

Both absolute and relative values of the heaters' power had to be balanced to reach the desired target temperature and low gradients in the Bi solution. Modeling shows that the temperature field throughout the Bi solvent has an interval of less than $1 \mathrm{~K}$ around the target temperature at the solvent surface of $600{ }^{\circ} \mathrm{C}$ when fixing each top heater to $38 \mathrm{~W}$ and the bottom heater to $117 \mathrm{~W}$. The global temperature field of the furnace under this heater arrangement is shown in the left part of figure 5 .

An important point is the question how the global gas flow might influence the temperature field in the vicinity of the solvent. The gas convection inside of the closed furnace is driven by the buoyant force due to temperature differences. As the right part of figure 5 shows, the global gas flow circulation remains essentially outside of the region of heater and solvent and it is even very weak in the dome region.

Differences in the thermal behavior of the equipment under vacuum and when filled with 1 bar $\mathrm{N}_{2}$ are notable, but tolerable. The magnitude of thermal fluctuations of the loop-controlled bottom heater (automatically tuned PID parameters) increases from $\sigma_{x}^{v a c}=0.08 \mathrm{~K}$ at vacuum to $\sigma_{x}^{N_{2}}=0.50 \mathrm{~K}$ for TC3 and $\sigma_{x}^{N_{2}}=0.26 \mathrm{~K}$ for TC4 at gas atmosphere when referring to the standard deviation of the temperature $\left(\sigma_{x}\right)$ as shown in figure 6 . However, the gas atmosphere reduces thermal gradients in the growth region significantly, as demonstrated by the strong decrease of the difference of the temperature signals (cf. left vs. right part of figure 6). The absolute offset of both thermocouple signals comes from different conversion procedures of the thermoelectric voltage into the temperature value. Other then the input module for TC4 the input module for TC3 is especially designed for the conversion of thermoelectric voltages. The precision of the temperature control of $\mathrm{X}$-oven when equipped with the growth assembly has the best value at $500{ }^{\circ} \mathrm{C}\left(\sigma_{x}^{N_{2}}=0.10 \mathrm{~K}\right)$. At higher temperatures the precision is reduced again $\left(\sigma_{x}^{N_{2}}=0.22 \mathrm{~K}\right.$ at $\left.600{ }^{\circ} \mathrm{C}\right)$.

Heating rates up to $20 \mathrm{~K} / \mathrm{min}$ and cooling rates of $1 \mathrm{~K} / \mathrm{min}$ during the growth step have been applied for experiments. Due to the low heat capacity of the X-oven (see the rapid cooling after switching off the power in figure 7) there is an immediate response to setpoint values changes at rates as indicated above. 
Fig. 5 Left side: Temperature field within the $\mathrm{X}$-oven $\left(\right.$ scale in ${ }^{\circ} \mathrm{C}$ ) with a temperature of $600{ }^{\circ} \mathrm{C}$ at the solventsubstrate interface and isotherms every three Kelvin in this area. Right side: Corresponding stream line pattern of the gas flow (scale in $\mathrm{cm}^{3} / \mathrm{s}$ ). (Online color at www.crt-journal.org)
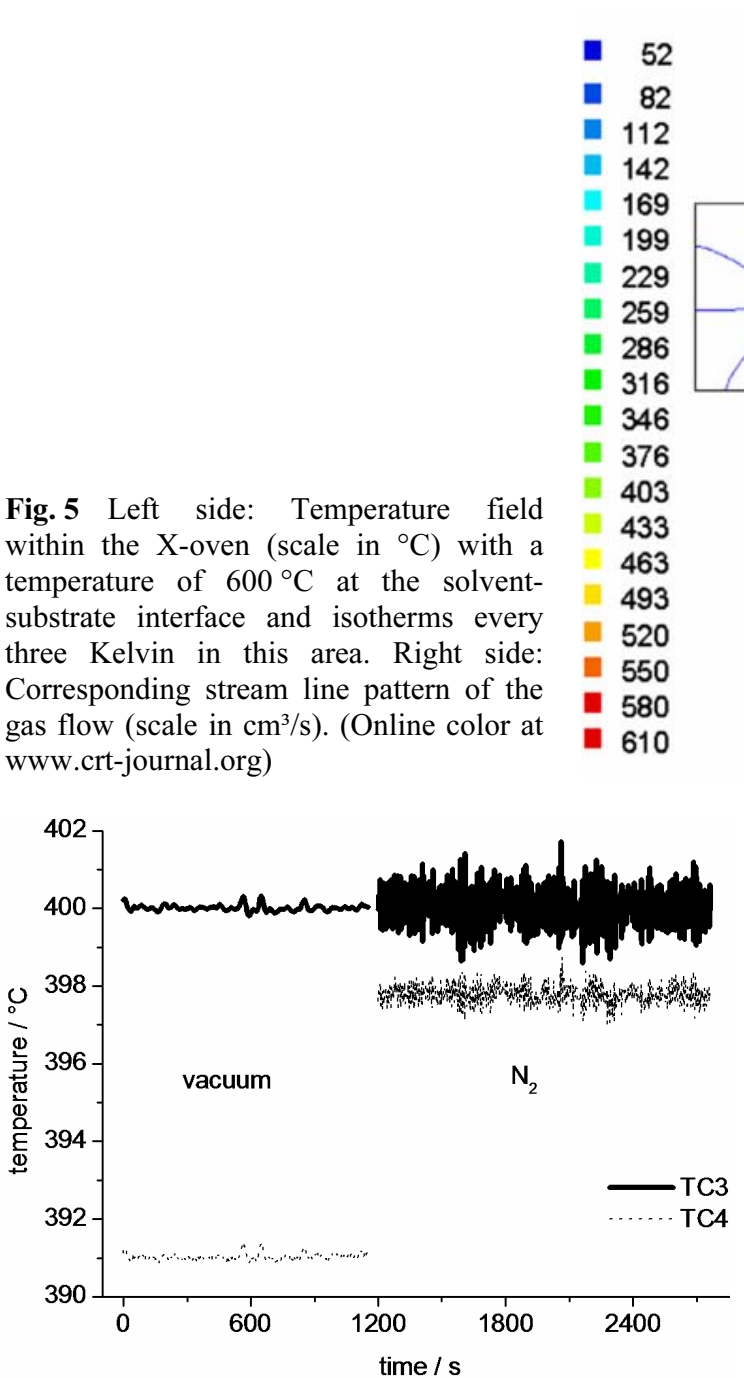

Fig. 6 Performance of temperature control at $400{ }^{\circ} \mathrm{C}$ above the bottom heater without growth assembly as measured with TC3 (upper curves) and TC4 (lower curves): (left part) under vacuum, and (right part) under 1 bar $\mathrm{N}_{2}$. The standard deviation of temperature amounts at vacuum to $\sigma_{x}^{v a c}=0.08 \mathrm{~K}$ (both $\mathrm{TCs}$ ) and at gas atmosphere to $\sigma_{x}^{N_{2}}=0.50 \mathrm{~K}(\mathrm{TC} 3)$ and $\sigma_{x}^{N_{2}}=0.26 \mathrm{~K}$ (TC4).
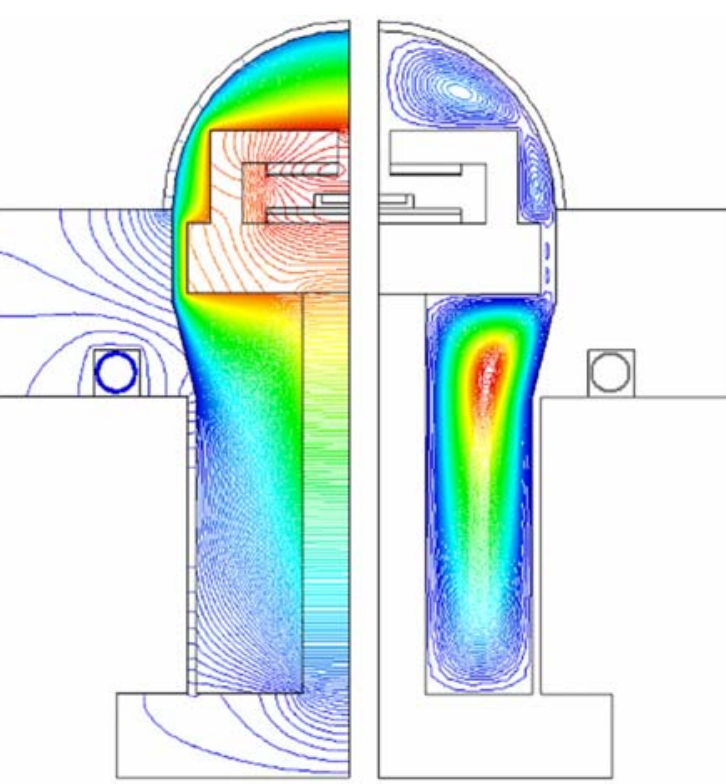

2.47

5.21

7.95

10.7

13.4

16.2

18.9

21.6

- 24.4

27.1

29.9

32.6

35.4

38.1

40.8

43.6

46.3

49.0

- 51.8

- 54.5

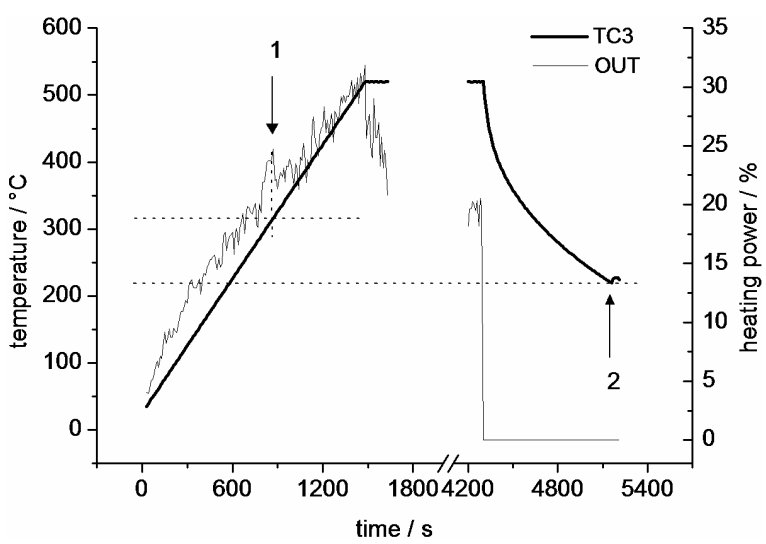

Fig. 7 The relative output power of the bottom heater (OUT: thin line) and the thermocouple (TC3: thick line) indicate melting (arrow 1) and freezing (arrow 2) of the solution in the course of the experiment.

The heating setup is sensitive enough to register the melting and freezing of the Bi solution. The melting can be detected by tracing the power signal. During heating a sharp decrement of the power value of the bottom heater (mark 1 in figure 7) signals the end of melting. On the other hand, the freezing during natural cooling appears as a temporary increase in the temperature of TC3 (marked as 2 in figure 7). The non-equilibrium conditions during the heating/cooling lead to a pronounced deviation from the melting point of $\mathrm{Bi}\left(271.3^{\circ} \mathrm{C}\right)$ of the temperatures indicating the phase transition as marked by the dotted lines in figure 7 .

During cooling to the freezing point the solution is decomposing. In the case of step 2 of the growth assembly preparation, the Si crystallites formed by homogeneous nucleation swim up due to the lower density and collect at the surface of the eventually solidifying Bi melt as revealed by a combination of SEM and EDX investigation (cf. Fig. 8). These Si crystallites, together with the added Ge grain, have to be dissolved anew in the first stage of the X-ray experiments when reaching the wanted liquidus temperature. 
In preliminary tests using conventional LPE equipment a significant bending of thin Si substrates with a radius in the range of centimeter has been observed when growing Ge containing layers. The bending of such substrates acts as strain relief and promotes both the shift to a higher Ge content and to a lower degree of supersaturation necessary to initiate the growth in comparison with normally used rigid substrates [12]. Without Ge no bending took place. Therefore, differences in surface tension of the solution-substrate interface and the substrate-gas surface do not play a substantial role for bending. Applying equation 1, the abovementioned bending radius corresponds to Ge deposits in a realistic order of magnitude. A layer of $30 \mathrm{~nm}$ pure Ge on the $20 \mu \mathrm{m}$ thick Si foil leads to a bending radius of $5.6 \mathrm{~cm}$. Such distortion impedes a proper X-ray investigation. The plate with the rectangular opening glued on the backside of the Si foil turned out to be the most effective way to prevent deformation.
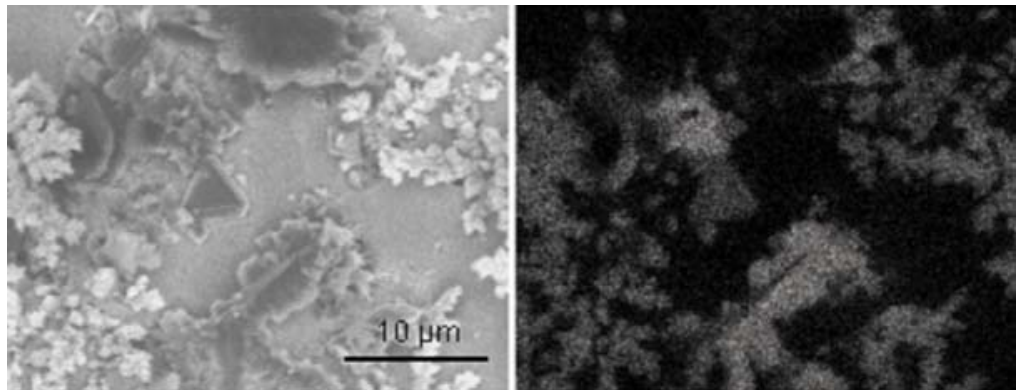

Fig. 8 SEM $(256 \times 200$ pixel $)($ left $)$ and the corresponding EDX mapping of the $\mathrm{Si} \mathrm{K}_{\alpha}$ line (right) of the same location on the ingot surface.

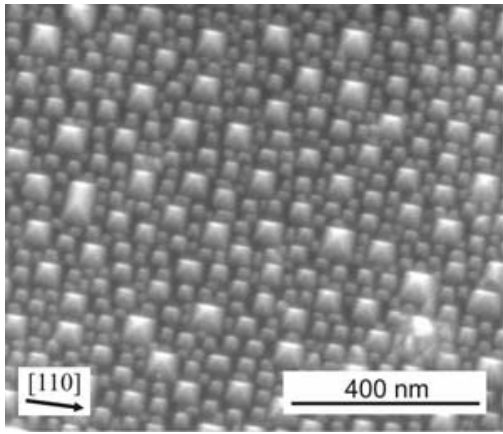

Fig. 9 SEM micrograph with pyramids grown in a X-oven experiment.

There is experimental evidence that growth of $\mathrm{SiGe}$ pyramids takes place in the X-oven with growth assemblies prepared in the above described manner as can be seen in figure 9. Etching provokes the slight rounding of the pyramidal faces.

Figure 10 depicts three selected CCD frames of the intensity distribution in the vicinity of the 004 reflection in the 110 zone. The upper intensity distribution results from the silicon substrate. The intensity distribution of the silicon-germanium islands will appear at smaller $q_{001}$ values because the $\mathrm{Si}(001)$ substrate has a smaller vertical lattice parameter than the SiGe islands. The first signal caused by the emerging SiGe islands appears at a temperature of $536{ }^{\circ} \mathrm{C}$ according to a germanium content of $30 \%$. By further cooling a part of the signal is shifted to smaller $\mathrm{q}_{001}$ values according to a germanium content of $50 \%$.

The diffraction experiments will be described in more detail in a subsequent paper. The experimental setup for the in situ X-ray investigations and first results of measurement are reported [13].

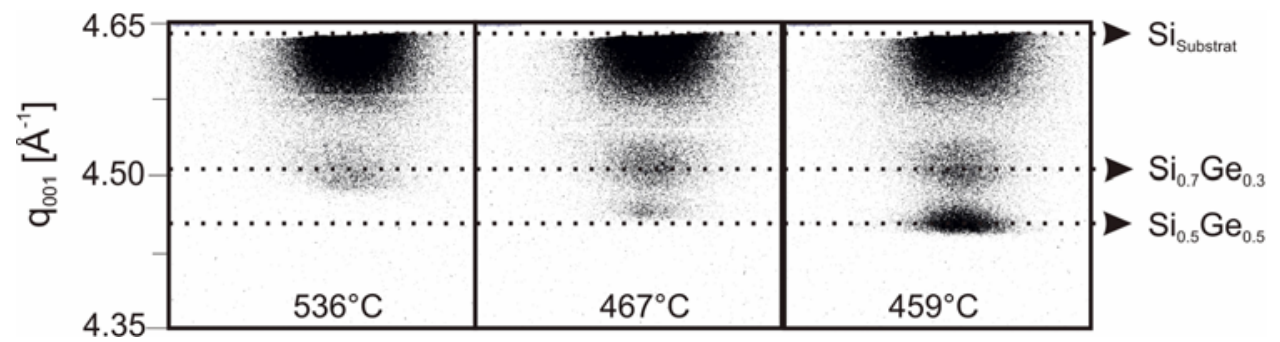

Fig. 10 Three CCD frames showing the intensity distribution of SiGe-island 004 reflections in relation to the 004 reflection of the Si substrate at different temperatures during cooling of the growth solution.

\section{Conclusions}

Equipment for in situ X-ray investigation of SiGe nano-island growth has been developed. The growth furnace fulfills the requirements for experiments at a synchrotron beamline. The thermal field and the gas flow inside the equipment have been modeled. Dimensioning of heaters and the determination of thermal gradients in the growth region resulted from these calculations. The thermally rapid X-oven is connected to a high-performance 
temperature controller that is able to maintain the temperature in the vicinity of the growth assembly with a precision of $0.1 \mathrm{~K}$ at the preferred temperature of $500^{\circ} \mathrm{C}$ for growth.

The procedure for preparation of the growth assembly has been adapted to the demands of beamline experiments. Three steps in a conventional LPE equipment are necessary to create a suitable growth assembly that consists of a small graphite crucible filled with Bi and topped by a $20 \mu \mathrm{m}$ thick Si substrate. Thin (001) Si substrates have to be glued to a thick Si plate to prevent the bending during the SiGe deposition.

The in situ X-ray diffraction experiments confirm the formation of a concentration profile during the growth of SiGe-islands. Such profiles are known from ex situ investigations and are explained by increasing stress relief from the island base to the apex.

Acknowledgements This work has been supported both by the Deutsche Forschungsgemeinschaft (German Research Foundation) under contract HA 3495/5-1 and the Ministry of Education and Culture of the Federal State of Saxony-Anhalt as project NW3 within the scope of the research network of excellence "Nanostrukturierte Materialien".

\section{References}

[1] S. Christiansen, M. Albrecht, H. P. Strunk, and H. J. Maier, Appl. Phys. Lett. 64, 3817 (1994).

[2] H. Kirmse, R. Schneider, R. Otto, W. Neumann, M. Hanke, M. Schmidbauer, R. Köhler, H. Wawra, T. Boeck, I. P. Soshnikov, N. N. Ledentsov, Z. F. Krasilnik, and A. Novikov, in: Proceedings $13^{\text {th }}$ Conference on Microscopy of Semiconducting Materials, Cambridge, U.K., 2003, Institute of Physics Conference Series, Vol. 180, (IOP Publ., Bristol, U.K., 2003) pp. 115-118.

[3] J. Groenen, R. Carles, S. Christiansen, M. Albrecht, W. Dorsch, H. P. Strunck, H. Wawra, and G. Wagner, Appl. Phys. Lett. 71, 3856 (1997).

[4] M. Schmidbauer, Th. Wiebach, H. Raidt, M. Hanke, R. Köhler, and H. Wawra, J. Phys. D 32, A230 (1999).

[5] M. Hanke, M. Schmidbauer, D. Grigoriev, H. Raidt, P. Schäfer, R. Köhler, A.-K. Gerlitzke, and H. Wawra, Phys. Rev. B 69, 075317 (2004).

[6] M. Hanke, M. Schmidbauer, R. Köhler, F. Syrowatka, A.-K. Gerlitzke, and T. Boeck, Appl. Phys. Lett. 84, 5228 (2004).

[7] W. Dorsch, H. P. Strunk, H. Wawra, G. Wagner, J. Groenen, and R. Carles, Appl. Phys. Lett. 72, 179 (1998).

[8] P. O. Hansson, E. Bauser, M. Albrecht, and H. P. Strunk, in: Gettering and Defect Engineering in Semiconductor Technology, edited by H.G. Grimmeis, M. Kittler, H. Richter, Solid State Phenomena, Vol. $32-33$ (Scitec Publications, Zürich, 1993), pp. 403-408.

[9] J. P. Fleurial and A. Borshchevsky, J. Electrochem. Soc. 137, 2928 (1990).

[10] Beamline BW2 of DORIS III at HASYLAB, Germany. http://hasylab.desy.de/facilities/doris_iii/beamlines/bw2/index_eng.html (accessed April 28, 2008).

[11] G. H. Olsen and M. Ettenberg, J. Appl. Phys. 48, 2543 (1977).

[12] Th. Teubner and T. Boeck, J. Cryst. Growth 289, 366 (2006).

[13] S. Deiter, M. Hanke, C. Eisenschmidt, and T. Boeck, in: HASYLAB Annual Report 2007, Hamburg, pp. $633-634$. http://hasyweb.desy.de/science/annual_reports/2007_report (accessed May 28, 2008). 